\title{
Familial juvenile hypertrophy of the breast
}

INSERM

\section{Source}

INSERM. (1999). Orphanet: an online rare disease and orphan drug data base. Familial juvenile hypertrophy of the breast. ORPHA:180176

Familial juvenile hypertrophy of the breast is a rare breast malformation disorder characterized by unilateral or bilateral, symmetrical or asymmetrical, uncontrolled, rapid and massive enlargement of the breast(s) in peripubertal females, occurring in various members of a family. Additional associated manifestations may include skin hyperemia, dilated subcutaneous veins, skin necrosis, kyphosis, lordosis and anonychia. Growth and development are otherwise normal. 